\title{
Analysis of six fungicides and one acaricide in still and fortified wines using solid-phase microextraction-gas chromatography/tandem mass spectrometry
}

Joana Martins, Cristina Esteves, Ana Limpo-Faria, Paulo Barros, Natália Ribeiro, Tomás Simões, Manuela Correia, Cristina Delerue-Matos

\section{ABSTRACT}

A multiresidue gas chromatographic method for the determination of six fungicides (captan, chlorthalonil, folpet, iprodione, procymidone and vinclozolin) and one acaricide (dicofol) in still and fortified wines wasdeveloped. Solid-phase microextraction (SPME) was chosen for the extraction of the compounds from the studied matrices and tandem mass spectrometry (MS/MS) detection was used. The extraction consists in a solvent free and automated procedure and the detection is highly sensitive and selective. Good linearity was obtained with correlation coefficients of regression $\left(R^{2}\right)>0.99$ for all the compounds. Satisfactory results of repeatability and intermediate precision were obtained for most of the analytes (RSD $620 \%$ ). Recoveries from spiked wine ranged from $80.1 \%$ to $112.0 \%$. Limits of quantification (LOQs) were consider- ably below the proposed maximum residue limits (MRLs) for these compounds in grapes and below the sug-gested limits for wine (MRLs/10), with the exception of captan.

Keywords: Fungicide, Acaricide, SPME, GC-MS/MS, Wine

\section{Introduction}

Monitoring of pesticide residues has received much attention in the last few years. As regards vineyard protection, the use of these compounds may result in the presence of residues in the wine, thus compromising the safety of this product (Correia, Delerue-Matos, \& Alves, 2000; Oliva, Navarro, Barba, \& Navarro, 1999; Patil et al., 2009). The presence of pesticides in grapes may result from direct applications and/or from indirect sources, such as contaminated agro-inputs. Besides the health hazards that may be caused by pesticide residues, the sensorial quality of wine may also be altered, affecting the marketability of the product (Patil et al., 2009).

The most common pests of vine are downy mildew (Plasmopara viticola), powdery mildew (Uncicula necator) and gray mold (Botrytis cinerea) (Cabras \& Angioni, 2000; Garau et al., 2009; González- Rodríguez, Cancho-Grande, Torrado-Agrasar, SimalGándara, \& Mazaira-Pérez, 2009). Fungicides are intensively used in the preven- tion/treatment of diseases of grapes for vinification. These com- pounds are typically applied close to harvest (Sandra et al., 2001). Among the fungicides, iprodione, procymidone and vinclozolin are commonly used in vineyard protection (Garcia, Melgar, \& Fernán- dez, 1999; Sandra et al., 2001). Captan and folpet (Cabras \& Angioni, 2000; Cunha, Fernandes, Alves, \& Oliveira, 2009) and chlorthalonil (Patil et al., 2009) are fungicides also used in the pest treatments of grapevines. Dicofol is widely used as an acaricide and it is also applied in vineyard protection (Soleas, Yan, Hom, \& Goldberg, 2000). Although the correct use of pesticides does not cause a threat to human health and the environment, inappropriate treatments of crops may result in undesirable pesticide residues in grapes that can be transferred to the wine (González-Rodríguez et al., 2009).

During vinification, pesticides are subjected to a number of steps that reduce significantly the residue levels, so their contents in wines are significantly lower than in grapes (Cabras \& Angioni, 2000; Cabras et al., 1997; Flamini \& Panighel, 2006; Navarro, Barba, Oliva, Navarro, \& Pardo, 1999; Otteneder \& Majerus, 2005). Therefore, sensitive and selective analytical methods are required to detect pesticide residues in wine.

Until now, the European Commission (EC) has established pesticide maximum residue levels (MRLs) in grapes, but not in wine. Since 1st September 2008, a new legislative framework on pesticide residues is applicable (EC Regulation No. 396/2005) completing the harmonisation and simplification of the pesticide maximum residue levels throughout the European Union. However, pesticides MRLs for wine have been suggested in order to guarantee as much as possible the safety of the beverage. Otteneder and Majerus (2005) suggested that a limiting value could be estimated considering a reduction of $90 \%$ of the pesticide maximum residue levels in grapes, thus reaffirming the necessity of effective and sensitive methods todetect pesticide residues in wine.

Solid phase microextraction (SPME) is an alternative extraction method to traditional techniques, allowing complete elimination of 

solvents, blanks reduction and a decrease in extraction time. This method does not require complete removal of the analyte from the liquid matrix (Kataoka, Lord, \& Pawliszyn, 2000) and can be used for a wider range of applications than other techniques such as solid phase extraction (SPE), which requires an exhaustive extraction (Pawliszyn \& Arthur, 1990). The SPME simplicity of use, relatively short sample processing time and fibre reusability have made this method an attractive choice for many analytical applications such as the analysis of environmental, food, aromatic, forensic and pharmaceutical samples (Ouyang \& Pawliszyn, 2008). The need for higher selectivity and sensitivity, as well as the necessity for confirmation have been successfully achieved by cou- pling gas chromatography (GC) or liquid chromatography (LC) with mass spectrometry (MS) and tandem mass spectrometry (MS/MS)

(Economou, Botitsi, Antoniou, \& Tsipi, 2009; Flamini \& Panighel, 2006; Hiemstra \& Kok, 2007). The use of these chromatographic techniques coupled with MS or MS/MS, for the determination and/or confirmation of pesticides in still wine has been reported by some authors (Angioni et al., 2003; Cunha et al., 2009; González-Rodríguez et al., 2009; Likas, Tsiropoulos, \& Miliadis, 2007; Patil etal.,2009; Rose, Lane, \& Jordan, 2009; Sandra etal., 2001;Soleas et al., 2000; Vitali, Guidotti, Giovinazzo, \& Cedrone, 1998; Zambonin, Quinto, De Vietro, \& Palmisano, 2004).

Although many papers have been published regarding the determination of pesticide residues in wine, the application of these methods in the analysis of wines showing higher sugar and alcoholic levels is far more reduced. In this work, a SPME-GCMS/MS method was validated for the determination of six fungicides (captan, chlorthalonil, folpet, iprodione, procymidone and vinclozolin) and one acaricide (dicofol) both in still and in fortified wines (white and red). In this study "fortified wine" refers to a wine in which fermentation is arrested before completion by alcohol distillate addition, allowing sugar and alcoholic content to be higher (around $80-100 \mathrm{~g} / \mathrm{L}$ total sugars and $19-22 \%$ alcohol strength $(\mathrm{v} / \mathrm{v})$ ) while "still wine" refers to a wine obtained by com-plete fermentation, thus having lower sugar and alcoholic contents.

\section{Materials and methods}

\subsection{Solutions and reagents}

Captan (99.1\%), chlorthalonil (99.2\%), folpet (99.9\%), procymidone (99.9\%), vinclozolin (99.5\%), iprodione (99.3\%) and dicofol $(97.6 \%)$ analytical standards were supplied by Riedel-de Häen (SeeIze, Germany).

Individual pesticide stock solutions ( $1 \mathrm{~g} / \mathrm{L}$ ) where prepared in methanol (99.9\%), supplied by Riedel-de Häen (Seelze, Germany), and stored under refrigeration $\left(2-6{ }^{\circ} \mathrm{C}\right)$. A stock standard mixture solution containing all pesticides $(7.97 \mathrm{mg} / \mathrm{L}$ captan, $7.98 \mathrm{mg} / \mathrm{L}$ chlorthalonil, $1.66 \mathrm{mg} / \mathrm{L}$ dicofol, $7.16 \mathrm{mg} / \mathrm{L}$ folpet, $28.97 \mathrm{mg} / \mathrm{L}$ procymidone, $3.82 \mathrm{mg} / \mathrm{L}$ vinclozolin and $104.7 \mathrm{mg} / \mathrm{L}$ iprodione) was also prepared in methanol, weekly, and stored under refrigeration $\left(2-6{ }^{\circ} \mathrm{C}\right)$.

Matrix-matched standards (at six levels for captan, chlorthalonil, dicofol, procymidone and vinclozolin and at five levels for folpet and iprodione) were prepared in different types of wine, previously analyzed for the absence of compounds. Four experi- mental blends of wine (blends of still white wine, still red wine, fortified white wine and fortified red wine), characterized in Table 1, were obtained from commercial wines in order to achieve a representative composition and a sufficient volume of wine for all the study. The wine blend samples were spiked with different volumes of the standard mixture solution. The quantification was based on six-point external calibration graph (five-point in the case of folpet 
and iprodione) obtained by plotting the peak areas against the the-oretical standard concentration.

\subsection{SPME procedure}

SPME extraction was performed in a Combipal MH 01-00B autosampler (CTC Analytics AG, Zwingen, Switzerland). SPME fibres (Supelco, Bellefonte, USA) were conditioned according to the sup-plier's instructions. The extraction procedure was performed using $20 \mathrm{~mL}$ clear glass vials (La-Pha-Pack, Langerwehe, Germany). Wine

blend samples of $19 \mathrm{~mL}$ were extracted by immersion of a $100 \mathrm{Im}$ polydimethylsiloxane (PDMS) coated fibre. The extraction condi- tions were: extraction temperature $35^{\circ} \mathrm{C}$, agitator speed $250 \mathrm{rpm}$ and extraction time $60 \mathrm{~min}$. After extraction and desorption, fibre conditioning was performed for $5 \mathrm{~min}$ in the presence of nitrogen (99.995\%).

\subsection{GC analysis}

Gas chromatographic analyses were performed in a FocusGC, equipped with a split/splitless injector (Thermo Fisher Scientific, Waltham, MA, USA). The analytical column used was a TR-5MS

( $30 \mathrm{~m} \times 0.25 \mathrm{~mm} \mathrm{ID} \times 0.25 \mathrm{Im}$ film thickness) coated with $5 \%$ phenyl methylpolysiloxane stationary phase (Thermo Fisher Scientific, Waltham, MA, USA). The carrier gas, high-purity helium (99.9999\%), maintained at a constant pressure of $50 \mathrm{kPa}$, was also used as the collision gas at the ion trap chamber for MS/MS tests. The split/splitless injection port was maintained in splitless mode for $3 \mathrm{~min}$ and set at a fixed temperature of $250{ }^{\circ} \mathrm{C}$. SPME desorption was carried out in the injector port for $6 \mathrm{~min}$. The oven tempera- ture programme used for the analyses was the following: initial temperature $80^{\circ} \mathrm{C}$ for $5 \mathrm{~min}$, raised to $300^{\circ} \mathrm{C}$ at a rate of $5{ }^{\circ} \mathrm{C} / \mathrm{min}$ and kept for $10 \mathrm{~min}$.

Gas chromatographic conditions were based on the study devel- oped by Vitali et al. (1998) with few adaptations. The initial oven temperature was kept during 5 and not during $2 \mathrm{~min}$, and the final oven temperature was $300^{\circ} \mathrm{C}$ instead of $250^{\circ} \mathrm{C}$.

\subsection{Mass spectrometry detection}

Pesticide retention times were determined in full scan mode, after which the MS/MS conditions were optimized in order to allow the correct identification of each pesticide, as well as good signal to noise ratios for MS/MS detection. A PolarisQ ion trap mass spec- trometer (Thermo Fisher Scientific, Waltham, MA, USA) operated in the electron impact (EI) mode was used. The ion source and transfer line temperatures were set at 250 ${ }^{\circ} \mathrm{C}$ and $280^{\circ} \mathrm{C}$, respec-

tively. The emission current of the ionization filament was set at $250 \mathrm{IA}$, generating electrons with $70 \mathrm{eV}$ and the electrons multi- plier voltage was $1850 \mathrm{~V}$. The analyses were carried out with a fil-

ament-multiplier delay of $5 \mathrm{~min}$. The mass spectrometer was calibrated frequently to perfluorotributylamine (PFTBA) through an automatic tune process. Some MS/MS conditions used are listed in Table 2. Quantification of each analyte was performed based on total ion count (TIC) after the fragmentation of the selected parent ion or on the base peak (Table 2). Instrument control and data acquisition were managed by a personal computer running the X-Calibur software (version 1.4).

The parent ions were chosen according to the MS spectra obtained in full scan mode (ions with the highest relative abundance), and considering the data on the pesticide's parent ions referred by other authors in the literature. Five excitation voltage values were studied $(1,1.1,1.2,1.3$ and 1.4$)$ for each pesticide and for the parent ion. The optimum values were selected. 
Table 1

Characterization of the wine blends used in this study.

\begin{tabular}{|c|c|c|c|c|c|c|}
\hline $\begin{array}{l}\text { Wine blends } \\
\text { c title }\end{array}$ & Alcoholometri & $\begin{array}{l}\mathrm{pH} \\
\text { acidity }\end{array}$ & Volatile & $\begin{array}{l}\text { Total } \\
\text { acidity }\end{array}$ & $\begin{array}{l}\text { Reducing } \\
\text { sugars }\end{array}$ & Glycerol \\
\hline & $(\%, v / v)\left(20^{\circ} \mathrm{C}\right)$ & & (g/L acetic acid) & (g/L tartaric acid) & $(\mathrm{g} / \mathrm{L})$ & $(\mathrm{g} / \mathrm{L})$ \\
\hline $\begin{array}{l}\text { Still white } \\
\text { Still red } \\
\text { Fortified white } \\
\text { Fortified red }\end{array}$ & $\begin{array}{l}12.77 \\
14.57 \\
19.30 \\
19.27\end{array}$ & $\begin{array}{l}3.24 \\
3.64 \\
3.58 \\
3.69\end{array}$ & $\begin{array}{l}0.45 \\
0.53 \\
0.22 \\
0.23\end{array}$ & $\begin{array}{l}5.77 \\
5.17 \\
3.26 \\
4.28\end{array}$ & $\begin{array}{c}18.6 \\
2.0 \\
106.2 \\
106.6\end{array}$ & $\begin{array}{c}7.1 \\
10.6 \\
3.0 \\
4.5\end{array}$ \\
\hline
\end{tabular}

Table 2

MS/MS conditions used in the proposed SPME-GC-MS/MS method.

\begin{tabular}{|c|c|c|c|c|c|c|}
\hline \multirow[t]{2}{*}{ Pesticide } & \multicolumn{2}{|l|}{ Isolation } & \multicolumn{2}{|c|}{ Excitation } & \multirow[t]{2}{*}{ MS/MS quantification } & \multirow[t]{2}{*}{ MS/MS confirmation } \\
\hline & Parent ion & Time & Voltage & Excitation energy ( $q$ & & \\
\hline $\begin{array}{l}\text { Captan } \\
\text { Chlorthaloni } \\
\text { Dicofol } \\
\text { Folpet } \\
\text { Iprodione } \\
\text { Procvmidon } \\
\text { Vinclozolin }\end{array}$ & $\begin{array}{l}264 \\
266 \\
139 \\
130 \\
314 \\
283 \\
212\end{array}$ & $\begin{array}{l}12 \\
12 \\
12 \\
12 \\
12 \\
12 \\
12\end{array}$ & $\begin{array}{l}1.2 \\
1.1 \\
1.1 \\
1.3 \\
1.1 \\
1.1 \\
1.2\end{array}$ & $\begin{array}{l}0.3 \\
0.3 \\
0.3 \\
0.3 \\
0.3 \\
0.3 \\
0.3\end{array}$ & $\begin{array}{l}226 a \\
\text { TIC } \\
\text { TIC } \\
102^{d} \\
\text { TIC } \\
\text { TIC } \\
\text { TIC }\end{array}$ & $\begin{array}{l}236.130 .204 .102 \\
266.231 .170 .205 .133 \\
111.139 .75 \\
102.115 .87 .75 \\
245.271 .188 \\
255.220 .173 .146 \\
172,177,145,212\end{array}$ \\
\hline
\end{tabular}

a Base peak; TIC - total ion count.

3. Results and discussion

\subsection{SPME conditions}

In a multiresidue method, the operational conditions used hardly match the optimum conditions for each analyte. Thus, compromise conditions have to be selected. Several types of fibre coatings are commercially available for SPME. The affinity of each type of fibre depends on the compounds characteristics (principle of "like dissolves like"). Non-polar PDMS fibre is preferred for the extraction of non-polar analytes. However, it can also be applied successfully to more polar compounds. This fibre coating is very rugged and is able to withstand high injector temperatures, up to about $300{ }^{\circ} \mathrm{C}$ (Kataoka et al., 2000). Besides these reasons, the PDMS fibre has been chosen because of its very low carryover between samples when compared with other type of coatings (Reyzer

\& Brodbelt, 2001).

The use of PDMS fibre coating for the extraction of pesticides in wine has been reported by some authors. Vitali et al. (1998) reported a SPME-GC-MS method for the determination of fourteen pesticide residues in wine, such as vinclozoline, procymidone, captan and folpet, using a $100 \mathrm{Im}$ PDMS coated fibre. Correia, DelerueMatos, and Alves (2001) developed a SPME-GC-ECD methodology for eight pesticides, including vinclozolin, procymidone, iprodione and folpet, in must and wine samples. The PDMS fibre coating was selected after preliminarily comparing the $100 \mathrm{Im}$ PDMS and $85 \mathrm{Im}$ polyacrilate (PA) fibres. Despite of the slightly higher performance of the PA coating over the PDMS for extracting the analytes from the wine matrix, the relative standard deviations were higher for the PA fibre (Correia et al., 2001). Sandra et al. (2001) reported a successful extraction procedure for the analysis of dicarboximide fungicides (iprodione, procymidone and vinclozoline) in wine using a PDMS coated stir bar sorptive extraction (SBSE) in combination with thermal desorption-capillary GC-MS analysis (TD-cGC-MS). Based on the referred studies, the PDMS fibre was selected for the present study.

Although SPME has a maximum sensitivity when equilibrium conditions are attained, full equilibration is not necessary for accurate and precise analysis (Kataoka et al., 2000). In this study an extraction time of $60 \mathrm{~min}$ was chosen enabling reproducible re- sults and adequate sensitivity. An agitator speed of $250 \mathrm{rpm}$ was 
suggested by the Combipal $\mathrm{MH}$ 01-00B autosampler supplier, allowing good reproducibility and at the same time to enhance the life time of the SPME fibre.

\subsection{Confirmation of the residues}

Pesticides were identified by retention time windows of the tar-get compound and comparison of the product ion mass spectra (MS/MS spectra) with the product ion mass spectra of standards, in wine matrix.

\subsection{Calibration and linearity}

Calibration curves were obtained for all pesticides by spiking the wine blend samples at six concentration levels for captan, chlorthalonil, dicofol, procymidone and vinclozolin and at five con- centration levels for folpet and iprodione. This procedure was re-peated in five different days and for the four different wine matrices. At the end, five calibration curves were obtained for each pesticide and for each matrix. The calibration ranges were chosen in order to include values lower than one tenth of the MRLs estab-lished for grapes (MRL/10), with the exception of captan which presented simultaneously a low response signal and a low MRL that did not permit to achieve that concentration level. Pesticides retention times and calibration ranges used, as well as the calcu-lated LOQs for each pesticide and the respective MRLs for grapes (EC Regulation No. 396/2005) are shown in Table 3.

The values of the slope and the correlation coefficient of regres- sion $\left(R^{2}\right)$ of representative calibration curves obtained for each pes-ticide in the matrices studied are presented in Table 4. Good linearity was achieved for the majority of the pesticides in all matrices $\left(R^{2}>0.99\right)$.

\subsection{Repeatability and intermediate precision}

The repeatability was assessed using wine blend samples spiked with pesticides at two different concentration levels. The tests were performed at least in four independent preparations and for all wine matrices. The results were expressed as relative standard deviation (RSD, \%) (data not shown). According to EC SANCO (2009), good results were obtained for the majority of the analytes 
Table 3

Retention times, calibration ranges, limits of quantification for each pesticide and respective MRLs for grapes according to EC Regulation No. 396/2005.

\begin{tabular}{|c|c|c|c|c|}
\hline Pesticide & Retention time (min) & Range (Ig/L) & LOQ (Ig/L) & $\mathrm{MRL}$ \\
\hline $\begin{array}{l}\text { Cantan } \\
\text { Chlorthalonil } \\
\text { Dicofol } \\
\text { Folpet } \\
\text { Iprodione } \\
\text { Procvmidone } \\
\text { Vinclozolin }\end{array}$ & $\begin{array}{l}35.70 \\
29.73 \\
33.86 \\
35.71 \\
41.91 \\
35.24 \\
31.19\end{array}$ & 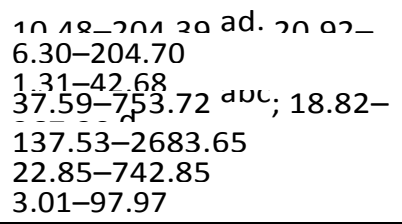 & $\begin{array}{l}52.10 \\
20.95 \\
4.37 \\
93.60 \\
274.70 \\
76.04 \\
10.03\end{array}$ & $\begin{array}{l}20 \\
3000 \\
2000 \\
5000 \\
10.000 \\
5000 \\
5000\end{array}$ \\
\hline
\end{tabular}

a Still white wine.

b still red wine.

C Fortified white

Table 4

Slopes and correlation coefficients of regression $\left(R^{2}\right)$ of representative calibration curves obtained, for each pesticide, in still and fortified wines.

\begin{tabular}{|c|c|c|c|c|c|c|c|c|}
\hline \multirow{2}{*}{$\begin{array}{l}\text { Pesticide } \\
\text { Captan }\end{array}$} & \multicolumn{2}{|c|}{ Still white wine } & \multicolumn{2}{|c|}{$\underline{\text { Still red wine }}$} & \multicolumn{2}{|c|}{ Fortified white wine } & \multicolumn{2}{|c|}{ Fortified red } \\
\hline & wis.te Slope & $R^{2} \cdot 9989$ & \$̧вpge & $R_{9978}^{2}$ & stope & $R^{2}-9969$ & \$lqpe & 0.9977 \\
\hline Chlorthalonil & 28515.4 & 0.9999 & 12054.0 & 0.9933 & 15336.4 & 0.9998 & 15505.9 & 0.9978 \\
\hline Dicofol & 163128.0 & R4924 & 142562.0 & 0.9997 & 90520.0 & 0.9957 & 82582.4 & 0.9979 \\
\hline Folpet & 362.3 & 0.9987 & 311.6 & 0.9941 & 506.9 & 0.9939 & 260.9 & 0.9939 \\
\hline Iprodione & 152.5 & 0.9994 & 122.0 & 0.9937 & 43.6 & 0.9958 & 42.6 & 0.9989 \\
\hline Procymidone & 6791.6 & 0.9994 & 4824.7 & 0.9991 & 2749.1 & 0.9964 & 2993.4 & 0.9934 \\
\hline Vinclozoline & 77567.4 & 0.9996 & 57594.3 & 0.9999 & 33211.4 & 0.9981 & 35767.2 & 0.9996 \\
\hline
\end{tabular}

Table 5

Intermediate precision ( $\mathrm{P} 4$ ), expressed as RSD (\%), and recovery, Rec. (\%), for the target pesticides in white and red wines.

\begin{tabular}{|c|c|c|c|c|c|c|c|c|c|c|c|c|c|}
\hline \multirow[t]{2}{*}{ Pesticide } & \multicolumn{4}{|c|}{ Conc. (Ig/L) Still white wine } & \multicolumn{3}{|c|}{ Still red wine } & \multicolumn{3}{|c|}{ Fortified white wine } & \multicolumn{3}{|c|}{ Fortified red wine } \\
\hline & & $\mathrm{RSD} \%$ & RSD $\%$ & $\operatorname{Re}$ & $\mathrm{RSD} \%$ & $\mathrm{RSD} \%$ & $\operatorname{Re}$ & RSD $\%$ & $\mathrm{RSD} \%$ & $\operatorname{Re}$ & RSD $\%$ & RSD $\%$ & $\operatorname{Re}$ \\
\hline Captan & $\begin{array}{c}419.55 \\
204.40 \\
103.52 \\
52.10\end{array}$ & $\begin{array}{l}\text { las } \\
30.0 \\
23.5 \\
15.0\end{array}$ & $\begin{array}{l}6.6 \\
7.3 \\
9.9\end{array}$ & $\begin{array}{l}95 . \\
89 . \\
94 .\end{array}$ & $\begin{array}{l}\text { 31.9 } \\
33.6 \\
36.2 \\
61.1\end{array}$ & $\begin{array}{r}1 \text { lact } \\
1.5 \\
6.3 \\
8.3 \\
13.0\end{array}$ & $\begin{array}{c}101 . \\
95 . \\
90 . \\
97 .\end{array}$ & $\begin{array}{l}\text { 41.8 } \\
30.3 \\
40.1 \\
38.7\end{array}$ & $\begin{array}{r}\text { Lact } \\
2.6 \\
12.1 \\
16.4 \\
7.5\end{array}$ & $\begin{array}{c}99 . \\
104 . \\
91 . \\
94 .\end{array}$ & $\begin{array}{l}\text { 19.8 } \\
61.8 \\
38.7 \\
26.3\end{array}$ & $\begin{array}{r}22.0 \\
9.0 \\
13.5\end{array}$ & $\begin{array}{l}92 . \\
96 . \\
95 .\end{array}$ \\
\hline Chlorthalon & $\begin{array}{c}204.70 \\
103.68 \\
52.18 \\
20.95\end{array}$ & $\begin{array}{r}8.6 \\
8.4 \\
8.9 \\
11.2\end{array}$ & $\begin{array}{l}0.8 \\
2.7 \\
4.4 \\
7.8\end{array}$ & $\begin{array}{c}100 . \\
97 . \\
94 . \\
97 .\end{array}$ & $\begin{array}{l}21.2 \\
21.2 \\
23.8 \\
28.9\end{array}$ & $\begin{array}{l}0.8 \\
2.9 \\
3.3 \\
5.6\end{array}$ & $\begin{array}{c}101 . \\
94 . \\
95 . \\
97 .\end{array}$ & $\begin{array}{l}37.7 \\
33.6 \\
26.3 \\
30.0\end{array}$ & $\begin{array}{l}1.5 \\
5.2 \\
6.4 \\
7.9\end{array}$ & $\begin{array}{c}100 . \\
98 . \\
101 . \\
102 .\end{array}$ & $\begin{array}{l}54.4 \\
53.1 \\
53.5 \\
55.8\end{array}$ & $\begin{array}{l}1.1 \\
4.1 \\
2.1 \\
5.2\end{array}$ & $\begin{array}{r}99 . \\
102 . \\
105 . \\
93 .\end{array}$ \\
\hline Dicofol & $\begin{array}{l}42.68 \\
21.62 \\
10.88 \\
4.37\end{array}$ & $\begin{array}{c}17.6 \\
11.7 \\
8.3 \\
16.7\end{array}$ & $\begin{array}{r}2.3 \\
6.6 \\
4.9 \\
18.9\end{array}$ & $\begin{array}{c}100 . \\
100 . \\
102 . \\
98 .\end{array}$ & $\begin{array}{l}12.5 \\
12.7 \\
14.5 \\
18.4\end{array}$ & $\begin{array}{l}1.5 \\
5.3 \\
4.5 \\
2.0\end{array}$ & $\begin{array}{c}99 . \\
100 . \\
104 . \\
90 .\end{array}$ & $\begin{array}{l}61.4 \\
46.0 \\
39.4 \\
50.5\end{array}$ & $\begin{array}{r}2.3 \\
7.4 \\
8.0 \\
14.0\end{array}$ & $\begin{array}{c}98 . \\
106 . \\
107 . \\
92 .\end{array}$ & $\begin{array}{l}36.9 \\
36.5 \\
38.5 \\
39.7\end{array}$ & $\begin{array}{l}1.7 \\
3.3 \\
2.4 \\
6.3\end{array}$ & $\begin{array}{r}98 . \\
103 . \\
103 . \\
91 .\end{array}$ \\
\hline Folpet & $\begin{array}{c}753.72 \\
367.20 \\
185.98 \\
93.60\end{array}$ & $\begin{array}{l}44.7 \\
29.7 \\
27.7 \\
22.3\end{array}$ & $\begin{array}{l}2.0 \\
8.8 \\
4.6 \\
6.8\end{array}$ & $\begin{array}{c}101 . \\
96 . \\
93 . \\
99 .\end{array}$ & $\begin{array}{l}33.3 \\
32.1 \\
35.8 \\
43.8\end{array}$ & $\begin{array}{l}2.2 \\
9.2 \\
5.7 \\
9.8\end{array}$ & $\begin{array}{c}100 . \\
97 . \\
91 . \\
97 .\end{array}$ & $\begin{array}{l}40.1 \\
25.1 \\
48.7 \\
41.7\end{array}$ & $\begin{array}{r}3.3 \\
14.4 \\
22.8 \\
10.9\end{array}$ & $\begin{array}{c}98 . \\
111 . \\
88 . \\
92 .\end{array}$ & $\begin{array}{l}39.9 \\
32.1 \\
33.1\end{array}$ & $\begin{array}{c}2.4 \\
11.8 \\
7.5\end{array}$ & $\begin{array}{r}100 . \\
95 . \\
103 .\end{array}$ \\
\hline Iprodione & $\begin{array}{c}2683.65 \\
1359.25 \\
684.07 \\
274.70\end{array}$ & $\begin{array}{c}10.2 \\
7.0 \\
4.1 \\
9.0\end{array}$ & $\begin{array}{l}0.8 \\
2.8 \\
5.3 \\
6.0\end{array}$ & $\begin{array}{c}101 . \\
94 . \\
92 . \\
104 .\end{array}$ & $\begin{array}{l}16.7 \\
12.1 \\
13.9 \\
14.3\end{array}$ & $\begin{array}{l}0.7 \\
3.4 \\
2.0 \\
6.5\end{array}$ & $\begin{array}{r}101 . \\
94 . \\
96 . \\
103 .\end{array}$ & $\begin{array}{l}88.1 \\
76.4 \\
63.8 \\
56.0\end{array}$ & $\begin{array}{r}1.6 \\
7.2 \\
6.1 \\
21.7\end{array}$ & $\begin{array}{c}100 . \\
96 . \\
98 . \\
103 .\end{array}$ & $\begin{array}{l}18.4 \\
12.1 \\
17.9 \\
22.2\end{array}$ & $\begin{array}{r}1.4 \\
4.6 \\
10.6 \\
18.0\end{array}$ & $\begin{array}{r}98 . \\
103 . \\
112 . \\
80 .\end{array}$ \\
\hline Procvmido & $\begin{array}{c}742.85 \\
376.25 \\
189.35 \\
76.04\end{array}$ & $\begin{array}{l}7.1 \\
9.1 \\
9.0 \\
8.1\end{array}$ & $\begin{array}{l}0.6 \\
2.8 \\
3.4 \\
4.4\end{array}$ & $\begin{array}{c}99 . \\
100 . \\
101 . \\
99 .\end{array}$ & $\begin{array}{r}7.9 \\
5.9 \\
9.1 \\
11.9\end{array}$ & $\begin{array}{l}1.0 \\
4.0 \\
4.0 \\
4.8\end{array}$ & $\begin{array}{c}98 . \\
103 . \\
107 . \\
91 .\end{array}$ & $\begin{array}{l}53.0 \\
50.7 \\
45.4 \\
49.0\end{array}$ & $\begin{array}{l}0.7 \\
2.5 \\
3.7 \\
9.6\end{array}$ & $\begin{array}{c}98 . \\
104 . \\
106 . \\
95 .\end{array}$ & $\begin{array}{l}17.1 \\
15.5 \\
14.7 \\
15.1\end{array}$ & $\begin{array}{l}1.0 \\
3.5 \\
2.1 \\
4.8\end{array}$ & $\begin{array}{r}98 . \\
106 . \\
105 . \\
95 .\end{array}$ \\
\hline Vinclozolin & $\begin{array}{l}97.97 \\
49.62 \\
24.97\end{array}$ & $\begin{array}{l}7.9 \\
7.8 \\
8.9\end{array}$ & $\begin{array}{l}0.6 \\
2.2 \\
3.7\end{array}$ & $\begin{array}{c}100 . \\
99 . \\
98 .\end{array}$ & $\begin{array}{l}6.2 \\
7.4 \\
6.8\end{array}$ & $\begin{array}{l}0.4 \\
1.4 \\
2.9\end{array}$ & $\begin{array}{r}99 . \\
101 . \\
103 .\end{array}$ & $\begin{array}{l}54.1 \\
47.2 \\
42.3\end{array}$ & $\begin{array}{l}1.0 \\
3.2 \\
4.7\end{array}$ & $\begin{array}{r}99 . \\
101 . \\
104 .\end{array}$ & $\begin{array}{l}23.2 \\
21.5 \\
21.8\end{array}$ & $\begin{array}{l}0.8 \\
2.5 \\
3.5\end{array}$ & $\begin{array}{r}98 . \\
103 . \\
105 .\end{array}$ \\
\hline
\end{tabular}


est. conc. - estimated concentration.

(RSD 6 20\%). Captan and folpet were the most problematic compounds, regarding the repeatability results, presenting RSD P $20 \%$ for some concentration levels (RSD in the range $13.4-33.4 \%$ and
14.1-37.9\%, for captan and folpet, respectively). This was probably due to a partial degradation in the injector or/and during the chromatographic analysis. Values of RSD $65 \%$ were obtained for some 
pesticides, such as vinclozolin and procymidone, even at low concentration levels. The lowest RSD was obtained for chlorthalonil, in still red wine fortified at $204.70 \mathrm{Ig} / \mathrm{L}(1.2 \%)$, while the highest value was obtained for folpet, in still red wine, fortified at $367.20 \mathrm{lg} /$ L(37.9\%).
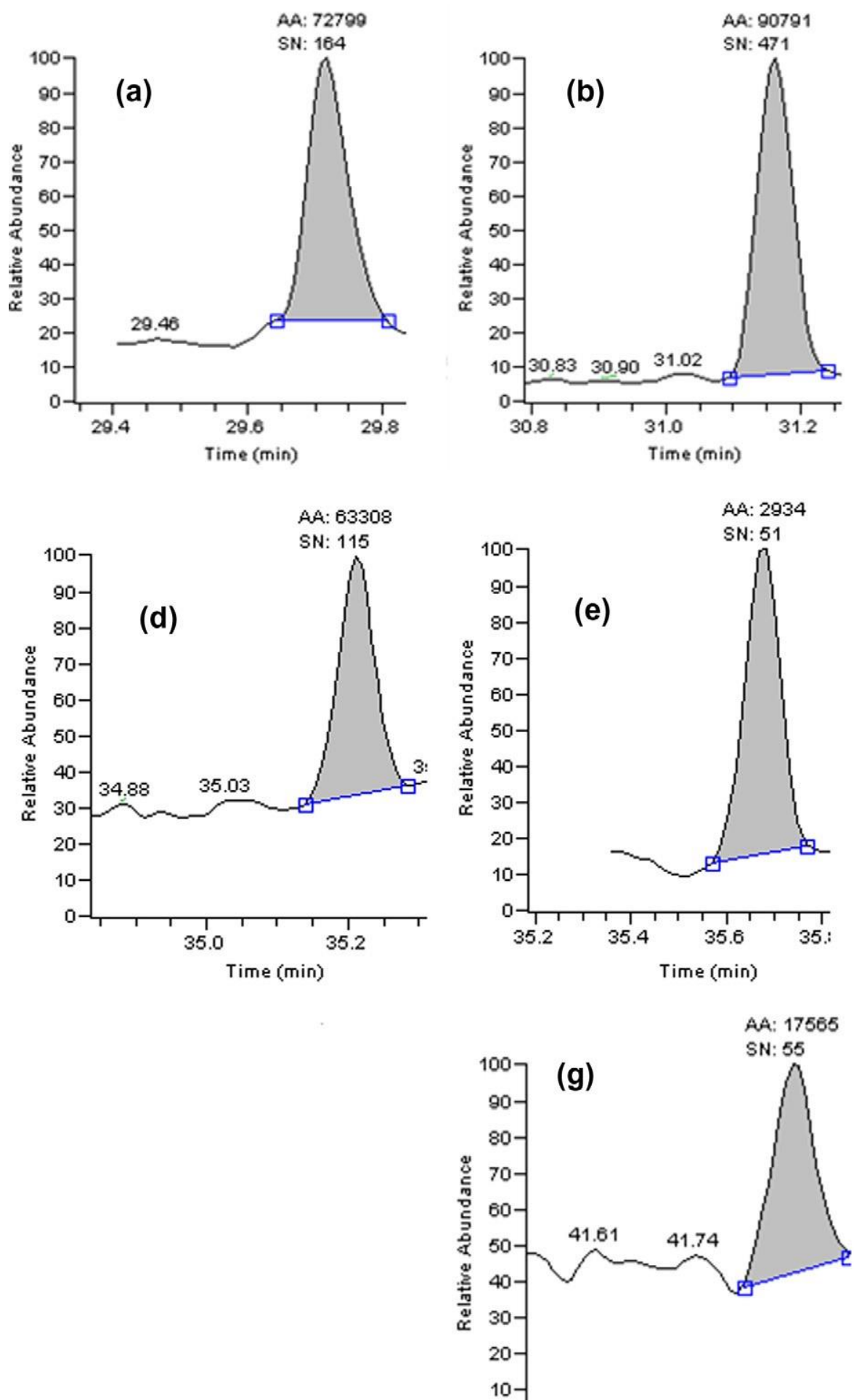

The intermediate precision was assessed using at least four independent preparations for each wine matrix. Each preparation was performed in a different day. Intermediate precision results, expressed as RSD (\%), are shown in Table 5. These results are presented according to two different calculation options: (i) RSDs
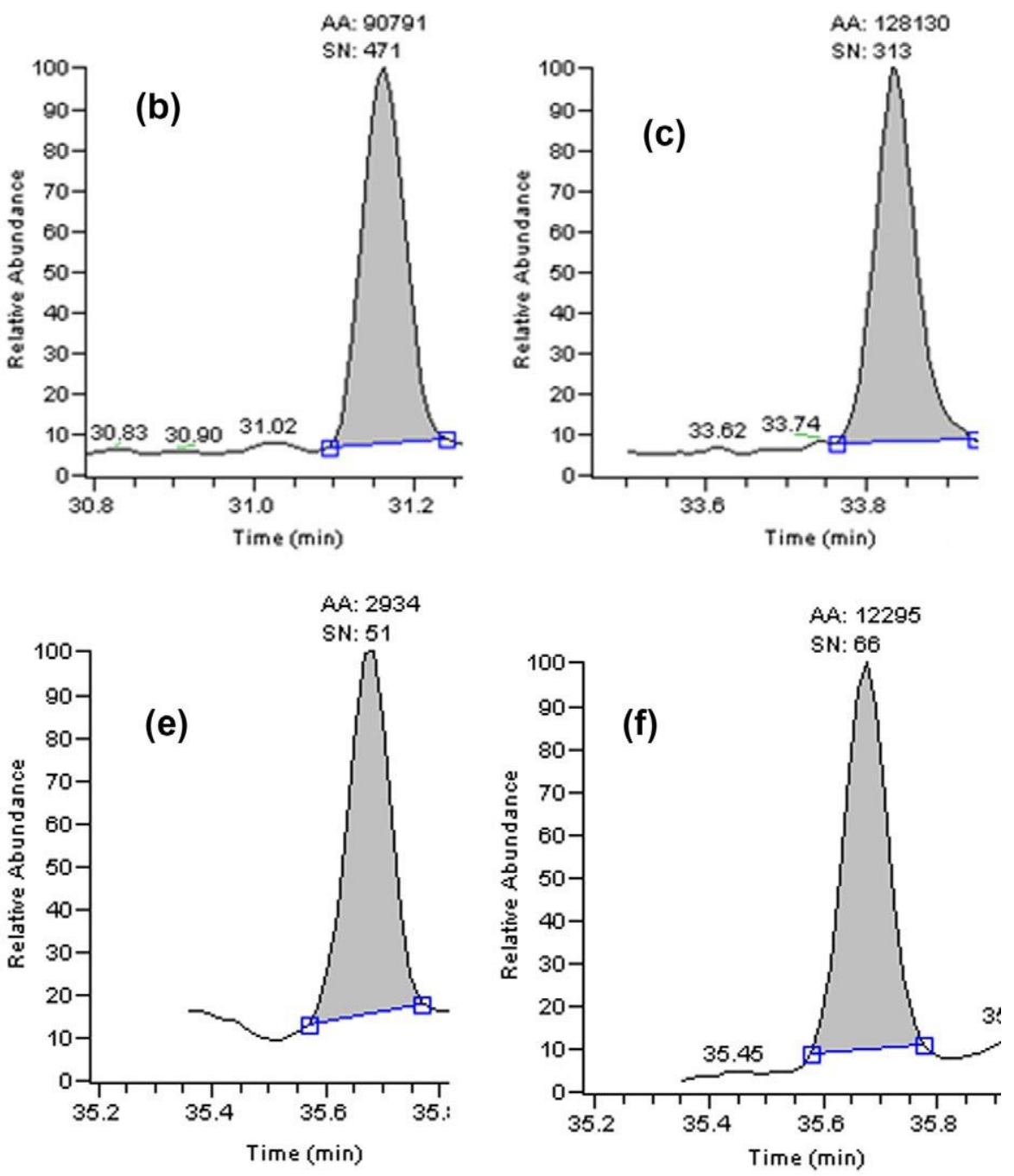

AA: 12295
$10-$

Fig. 1. SPME-GC-MS/MS chromatograms obtained for each analyzed pesticide, in fortified white wine: (a) chlorthalonil (6.30 Ig/L); (b) vinclozolin (3.01 Ig/L); (c) dicofol (1.31 Ig/L); (d) procymidone (22.8/5 Ig/L); (e) captan (20.92 Ig/L); (f) folpet (37.59 Ig/L);

(g) iprodione (137.53 Ig/L) (AA - peak area; SN - signal to hóise ratio). 41.8 

calculated using the obtained areas in the different days of analysis and (ii) RSDs calculated using "estimated concentration values". As mentioned before, five independent calibration curves were ob- tained for each pesticide in each wine matrix. As expected, differ- ent calibration curves were obtained in different days as a consequence of the variation in the response of the chromato- graphic system. Thus, considerable variations were notorious when comparing the values of the areas obtained for a pesticide, in a ma- trix, at the same concentration level, in different days. This situa- tion was overcome working with "estimated concentration values", obtained substituting the values of the areas in the calibra- tion curve of the respective day ofanalysis.

The RSDs obtained using "estimated concentration values"

(Table

5) were lower than those based in the peak areas since the first method takes into account the variations in the equipment response, as referred above. The RSDs based on area values are much larger and show clearly the inter-day variation. Thus, considering the RSDs based on "estimated concentration values", good results were obtained for the intermediate precision for most of the pesti- cides (RSD 6 20\%). Generally, the RSD values decreased as the con- centration increased, like it would be expected. An exception was observed for captan and folpet possibly due to their instability dur- ing the extraction and/or chromatographic steps, as above men-tioned. As regards the intermediate precision, the lowest RSD value was obtained for vinclozolin in still red wine fortified at $97.97 \mathrm{Ig} / \mathrm{L}(0.4 \%)$ and the highest value was obtained for folpet, in fortified white wine at $185.98 \mathrm{Ig} / \mathrm{L}(22.8 \%)$.

\subsection{Recovery}

Recovery results based on "estimated concentration values" are also presented in Table 5. Good recoveries were achieved for all the studied pesticides, according to EC SANCO (2009) (recovery val-

ues between $70 \%$ and $120 \%$ ). Recovery values ranged between $80.1 \%$, for iprodione in fortified red wine at $274.70 \mathrm{Ig} / \mathrm{L}$, and $112.0 \%$, for the same compound at $684.07 \mathrm{Ig} / \mathrm{L}$. As an example, the graphical repre-

sentation of the "estimated concentration values" versus theoretical concentration for the pesticide vinclozolin, in still red wine, based on the results obtained for five different calibration curves in five dif- ferent days, was described by the following equation: estimated con- centration $=$ theoretical concentration $+3 \times 10^{-14}$, with $R^{2}=0.9989$. The intercept is close to zero and the slope value is 1 , demonstrating that the estimated concentrations obtained are closed to the theo- retical concentration. Similar results were obtained for the other compounds.

\subsection{Limits of quantification}

Limits of quantification (LOQ) were estimated considering the repeatability and intermediate precision studies. For each pesticide, the lowest concentration level tested with RSD values $620 \%$ was considered (EC SANCO, 2009). LOQ values, expressed as Ig/L, are presented in Table 3, as well as the MRLs established for grapes according to EC Regulation No. 396/2005. The two values can be easily compared considering that the density of the wine samples used in this study is very close to 1 (the density of the wine samples ranged between 0.9921-0.9974 for still wines and 1.02081.0233 for fortified wines). Otteneder and Majerus (2005) have proposed as MRLs for wine one tenth of the MRLs established for grapes, based on an average pesticide concentration reduction of $90 \%$ of the initial levels in grapes, due to the vinification process.

Good LOQs were obtained for all pesticides with the exception of captan. This LOQ $(52.10 \mathrm{Ig} / \mathrm{L})$ was above the MRL established by the EC Regulation for grapes $(20 \mathrm{Ig} / \mathrm{kg}$ ) and consequently above the proposed limit of MRL/10. LOQ values ranged between $4.37 \mathrm{Ig} / \mathrm{L}$ for dicofol and $274.70 \mathrm{Ig} / \mathrm{L}$ for iprodione. Analyzing chromatographic 
peaks obtained for low concentration levels (Fig. 1), it can be seen that the equipment sensitivity allows achieving lower LOQ values than the estimated, if LOQs based in a signal to noise ratio of 10 are considered.

Interlaboratory comparisons, organized by the Bureau Interprofessionnel d'Études Analytiques (BIPEA, Gennevilliers, France) showed Z-Score values <2, for three pesticides using the proposedmethod (iprodion, procymidone and vinclozoline), in an organicred wine sample. The other analytes were not included in the inter-laboratory study.

\subsection{Limitations of the proposed method}

Regarding the results presented in Table 4, a significant matrix effect was observed and, for this reason, the analysis using matrix-matched standards is necessary.

Other limitations are related to compounds behaviour during analysis. Among the studied pesticides, some present low detector responses, such as captan, folpet and iprodione. Degradation of the pesticides captan and folpet may occur during GC analysis (Büttler and Hörmann, 1981) and decomposition of iprodione can occur in the GC column above $200{ }^{\circ} \mathrm{C}$, during thermal desorption at $300{ }^{\circ} \mathrm{C}$ and in the hot transfer line (Flamini \& Panighel, 2006). Neverthe- less, folpet and iprodione do not represent a concern to this meth-od because LOQs are 53 and 36 times lower, respectively, than theMRLs for these compounds.

Generally, the estimated LOQs allow ensuring that the MRLS established for grapes and also the suggested MRLs for wine (MRLs for established for grapes/10) are respected, except for captan. Still, captan and folpet do not seem to be problematic compounds inwine quality control since, according to literature, these com-pounds are totally or almost totally degraded during winemaking(Angioni et al., 2003; Flamini \& Panighel, 2006).

\section{Conclusions}

The proposed method allows the simple, rapid and automated determination of six fungicides and one acaricide in red and white wines, still or fortified. The method showed good recoveries $(80.1-112.0 \%)$ and precision, with an overall average repeatability of $11 \%$. With the exception of captan, the limits of quantification were sig- nificantly lower than the MRLs established for grapes and than the suggested limits for wine (MRLs/10) making this a very convenient method for the analysis of the selected pesticides in wine samples.

\section{References}

Angioni, A., Garau, V., Del Real, A. A., Melis, M., Minelli, E., Tuberoso, C., \& Cabras, P. (2003). GC-ITMS determination and degradation of captan during winemaking. Journal of Agricultural and Food Chemistry, 51, 6761-6766.

Büttler, B. \& Hörmann, W. D. (1981). High-pressure liquid chrómatographic

determination of captan, captafol and folpet residues in plant material. Journal of Agricultural and Food Chemistry, 29(2), 257260.

Cabras, P., \& Angioni, A. (2000). Pesticide residues in grapes, wine and their processing products. Journal of Agricultural and Food Chemistry, 48(4), 967-973. Cabras, P., Angioni, A., Garau, V. L., Minelli, E. V., Melis, M., \& Pirisi, F. M. (1997). Pesticides in the distilled spirits of wine and its byproducts. Journal of Agriculture and Food Chemistry, 45, 2248-2251.

Correia, M., Delerue-Matos, C., \& Alves, A. (2000). Multiresidue methodology for pesticide screening in wines. Journal of Chromatography A, 889, 59-67.

Correia, M., Delerue-Matos, C., \& Alves, A. (2001). Development of a SPME-GC-ECD methodology for selected pesticides in must and wine samples. Fresenius Journal of Analytical Chemistry, 369, 647-651.

Cunha, S. C., Fernandes, J. O., Alves, A., \& Oliveira, M. B. P. P. (2009). Fast low- pressure gas chromatography-mass spectrometry method for the determination of multiple pesticides in grapes, musts and wines. Journal of Chromatography A, 1216, 119-126.

Economou, A., Botitsi, H., Antoniou, S., \& Tsipi, D. (2009). Determination of multi- class pesticides in wines by solidphase extraction and liquid chromatography- tandem mass spectrometry. Journal of Chromatography A, 1216, 5856-5867. 
European Commission SANCO/2009/10684 - Method validation and quality control procedures for pesticide residues analyses in food and feed. <http://www.crlpesticides.eu/library/docs/fv/guidefinalversion.pdf> Accessed February 2010.

European Parliament and Council, Regulation (EC) No. 396/2005 of the European Parliament and of the Council of 23 February 2005 on maximum residue levels of pesticides in products of plant and animal origin and amending Council Directive 91/414/ECC. Off. J. Eur. Commun. L 70 of 16/03/2005, 1-16.

Flamini, R., \& Panighel, A. (2006). Mass spectrometry in grape and wine chemistry.

Part II: The consumer protection. Mass Spectrometry Reviews, 25, 741-774.

Garau, V. L., Abreu, S. M., Caboni, P., Angioni, A., Alves, A., \& Cabras, P. (2009). Residue- free wines: Fate of some quinone outside inhibitor (Qol) fungicides in the winemaking process. Journal of Agricultural and Food Chemistry, 57, 23292333.

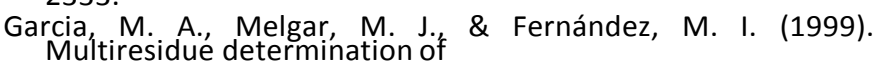

fungicides in wine. Bulletin of Environmental

Contamination and Toxicology, 62, 717-722.

González-Rodríguez, R. M., Cancho-Grande, B., Torrado-Agrasar, A., Simal-Gándara, J., \& Mazaira-Pérez, J. (2009). Evolution of tebuconazole residues through the winemaking process of Mencía grapes. Food Chemistry, 117, 529-537.

Hiemstra, M., \& Kok, A. (2007). Comprehensive multi-residue method for the target analysis of pesticides in crops using liquid chromatography-tandem mass spectrometry. Journal of Chromatography A, 1154, 3-25.

Kataoka, $\mathrm{H}_{\text {. }}$ Lord, H., \& Pawliszyn, J. (2000). Applications of solid'-phase

microextraction in food analysis. Journal of Chromatography A, 880, 35-62.

Likas, D. T., Tsiropoulos, N. G., \& Miliadis, G. E. (2007). Rapid gas chromatographic method for the determination of famoxadone, trifloxystrobin and fenhexamid residues in tomato, grape and wine samples. Journal of Chromatography A, 1150, 208-214.

Navarro, S., Barba, A., Oliva, J., Navarro, G., \& Pardo, F. (1999). Evolution of residual levels of six pesticides during elaboration of red wines. Effect of wine-making procedures in their disappearance. Journal of Agricultural and Food Chemistry, 47, 264-270.

Oliva, J., Navarro, S., Barba, A., \& Navarro, G. (1999). Determination of chlorpyrifos, penconazole, fenarimol, vinclozolin and metalaxyl in grapes, must and wine by on-line microextraction and gas chromatography. Journal of Chromatography A, 833, 43-51.

Otteneder, H., \& Majerus, P. (2005). Pesticide residues in wine, transfer from grapes.

Bulletin de I'O.I.V., 78(889-890), 173-181.

Ouyang, G., \& Pawliszyn, J. (2008). A critical review in calibration methods for solid-phase microextraction. Analytica Chimica Acta, 627, 184-197.

Patil, S. H. Banerjee, K., Dasgupta, S., Oulkar, D. P., Patil, S. B., Jadhav, M. R., Savant, R.

H., Adsule, P. G., \& Deshmukh, M. B. (2009). Multiresidue analysis of 83 pesticides and 12 dioxin-like polychlorinated biphenyls in wine by gas chromatographytime-of-flight mass spectrometry. Journal of ChromatographyA, 1216, 2307-2319.

Pawliszyn, J., \& Arthur, C. (1990). Solid phase microextraction with thermal desorption using fused silica optical fibers.

Analytical Chemistry, 62, 2148-2154. Reyzer, M. L., \& Brodbelt, J. S. (2001). Analysis of fire ant pesticides in water by solid- phase microextraction and gas chromatography/mass spectrometry or high- performance liquid chromatography/mass spectrometry. $436,11-20$.

Analytica Chimica Acta,

Rose, G., Lane, S., \& Jordan, R. (2009). The fate of fungicide and insecticide residues in Australian wine grape by-products following field application. Food Chemistry, 117, 634-640.

Sandra, P., Tienpont, B., Vercammen, J., Tredoux, A., Sandra, T., \& David, F. (2001). Stir bar sorptive extraction applied to the determination of dicarboximide fungicides in wine. Journal of Chromatography A, 928, 117-126.

Soleas, G. J., Yan, J., Hom, K., \& Goldberg, D. M. (2000). Multiresidue analysis of seventeen pesticides in wine by gas chromatography with mass-selective detection. Journal of Chromatography A, 882, 205-212.

Vitali, M., Guidotti, M., Giovinazzo, R., \& Cedrone, O. (1998). Determination of

pesticide residues in wine by SPME and GC/MS for consumer risk assessment.

Food Additives and Contaminants, 15, 280-287.

Zambonin, C. G., Quinto, M., De Vietro, N., \& Palmisano, F. (2004). Solid-phase microextraction-gas chromatography mass spectrometry: A fast and simple screening method for the assessment of organophosphorous pesticides residues in wine and fruit juices. Food Chemistry, 86, 269274. 